\title{
Using Performance Measurement to Evaluate \\ Strategic Human Resource Management Decisions: \\ Kodak's Experience With Profit Sharing
}

\author{
John W. Boudreau \\ Center for Advanced Human Resource Studies \\ School of Industrial and Labor Relations \\ Cornell University \\ and \\ Robert Berman \\ Eastman Kodak Company \\ Working Paper \#92-14
}

This research was carried out with support from the U.S. Army Research Institute, contract SRFC \#MDA903-87-K-0001. The views, opinions, and/or findings contained in this paper are those of the authors and should not be construed as an Official Department of the Army policy or decision.

This paper has not undergone formal review or approval of the faculty of the ILR School. It is intended to make the results of Center research, conferences, and projects available to others interested in human resource management in preliminary form to encourage discussion and suggestions. 


\section{Summary:}

Profit-sharing is frequently used to link employee performance and labor costs to the profitability of organizations. It represents a significant investment. Yet, 'managers' decisions regarding such human resource investments frequently do not use the same financial planning frameworks typical of other investments. This article presents a case study describing how one division at Eastman Kodak company used a strategic investment approach to plan and evaluate a profit-sharing program, and the role of performance measurement information in that approach. 


\section{Using Performance Measurement to Evaluate \\ Strategic Human Resource Management Decisions:}

\section{Kodak's Experience With Profit Sharing}

Compensation decisions command attention, perhaps more than any other human resource management activity. Everyone receives a paycheck in some form, and every line manager can clearly see the impact of compensation costs on the unit's bottom line. It is tempting to focus on compensation as a cost center. Many organizations make decisions such as work force reduction primarily in an effort to reduce labor costs. Yet, organizations seldom adopt strategies that set pay at the minimum. Instead they often provide more than the minimum amount of pay to attract, retain and motivate worker behaviors. Pay strategies also usually reflect a combination of tactics designed to fit the organization's goals. Frequently, these tactics attempt to link pay amounts to a measure of individual or organizational performance. Thus, most large organizations invest millions of dollars annually in planning, administering, and actually paying employees. Certainly, an important strategic role for performance assessment is to provide the link between pay and performance, and to serve as an indicator of the success of compensation programs.

For organizations investing millions of dollars in compensation, the question must be, "Are we getting a good return on our investment in compensation?" To answer this question requires that the organization consider compensation as more than simply a cost of doing business. Compensation must be considered an investment, with compensation costs representing the inflow of resources necessary to create a set of programs, leading to desired outcomes. These outcomes are evaluated, in part, based on actual and anticipated performance levels. 
Although much has been written about how to implement compensation programs (Milkovich \& Newman, 1990; Lawler, 1981), we know little about the decision processes used by managers to plan and evaluate such programs. Available data suggest that managers and employees may view profit-sharing programs positively, though employees generally prefer to receive pay in the form of base pay or individual incentives (Weitzman and Kruse, 1990). Unlike investments in new technology, advertising, financial instruments or acquisitions of new businesses, compensation investments are probably not routinely planned or evaluated using standard financial tools. This article focuses on one particular compensation program -- profit sharing, and describes how one organization used investment analysis tools to strategically plan a profit-sharing program. The approach not only demonstrates the value of applying financial tools to human resource management, it also suggests how performance measurement can better support human resource strategy.

\section{Compensation as a Strategic Investment}

Figure 1 illustrates the concept of investment analysis applied to compensation. Generally, any investment can be evaluated in terms of the resources required, the programs and strategies that result from the investment, and the valued outcomes produced by the programs and strategies. As the Figure shows, the model is cyclical. If the valued outcomes are sufficient to provide an attractive return based on the investment, then more resources are available, and future investments are justified.

As with any investment, compensation programs require using resources, such as administration, planning, and the actual cash value of the payout. From an investment perspective, these resources become available only through a competitive process in which alternative uses are considered. Simply put, the time, energy, and money used to pay 
employees could be invested in such things as new equipment, improvements in research facilities, higher advertising budgets, acquisition of new business, or simply as dividends to shareholders. Seen from this perspective, it is clear that the substantial resources devoted to compensation are not simply a fixed overhead cost. They should be managed just as carefully as other organizational investments.

One approach to managing these resources is to identify the programs and strategies that they support. Compensation strategies are usually described in terms of four familiar concepts (Milkovich \& Newman, 1991). These are pay level (how the overall amount of pay compares to other competing organizations), pay structure (how the pay of different jobs/roles within the organization compares), pay form (the method in which pay is distributed, such as the proportion of direct pay versus benefits), and pay administration (how the pay strategy is implemented, maintained and communicated). Profit sharing primarily affects pay form, though issues of pay structure and level were also relevant at Kodak, as we will see.

Compensation programs are often evaluated and planned merely in terms of whether they remain "on budget" (a resource perspective), or whether they are implemented and follow the planned guidelines (an activity perspective). From an investment perspective, however, this is like evaluating an investment in new technology only in terms of how much the technology costs and how many employees use it. Clearly, a critical variable is whether the use of the new technology affects results.

Planning and evaluating the valued outcomes of compensation programs is often the most difficult, but also the most crucial step. Such outcomes run the gamut from broad organization-level results (such as profits, return-on-investment, market share and overall quality) to individual-level results (such as performance ratings, absence, turnover, and 
individual output or sales levels). It is not our purpose to provide a comprehensive list of compensation outcomes here, but individual performance levels are usually a critical component of any such list. To have value, however, such performance levels must be measured and expressed in terms that link directly to the strategic goals of the compensation program. Because it is never possible to anticipate or even to measure the value of performance changes precisely, the financial tools supporting such an analysis must recognize uncertainty and help managers deal with it. Break-even analysis (Boudreau, 1984) has been proposed as just such a tool. The following case study illustrates how the investment framework of Figure 1 was applied using break-even analysis to better understand the level of performance outcomes necessary to justify a compensation investment.

\section{The Profit-Sharing Investment at Eastman Kodak Company}

Eastman Kodak Company represents a highly successful organization, employing 134,000 individuals around the world. It's success has been built largely on it's innovative and well-recognized products in three principal business segments: Imaging, Chemicals and Health. Kodak products include photographic films, paper and chemicals for amateur and professionals use; motion picture films, copiers/duplicators; electronic imaging products; industrial chemicals, filters and plastics; pharmaceuticals; diagnostic imaging film and equipment; and chemical analyzers. The organization has undergone several fundamental structural changes, evolving from a highly centralized structure to a more decentralized structure with identifiable profit centers (organized according to specific markets, such as professional film) and resource (or "cost") centers (organized according to their product, such as sensitized materials). During the last decade, the organization has also embraced principles 
of quality improvement and employee involvement, in an effort to speed product innovation, increase quality, and successfully contend with ever more nimble competitors.

The human resource management function has undergone a corresponding evolution. Decisions previously made at headquarters by specialists in each human resource function are now frequently made at the profit-center or cost-center level, by human resource generalists specifically assigned as partners with profit-center or cost-center line managers. The contribution of human resource managers, previously often evaluated by the efficiency with which standardized programs were administered, is now frequently evaluated by the contribution to profit-center or cost-center goals, jointly defined by line managers and human resource managers. Throughout the human resource organization, there is a drive to be more accountable for the results of decisions, not just the cost or administration of programs.

Historically, Kodak management's quantitative assessment of pay programs has primarily taken a resource perspective. New or proposed compensation programs were evaluated in terms of their viability based on their anticipated cost. Certainly, potential benefits of such programs were considered, but they were seldom incorporated into the planning process in a tangible and quantitative way. New compensation strategies might be rejected or accepted depending primarily on whether their budget exceeded some established level, or whether an informal assessment of their likely benefits produced a generally positive or negative impression among key decision makers. Also, because the profit-center or costcenter structure had emerged only recently, there was a strong tendency to reject human resource management initiatives that would significantly affect one unit as compared to others. The different units of the organization were located primarily in one geographic area, and often 
involved similar jobs. Thus, to avoid any perception of inequity across units, human resource policies had long been driven by a need for consistency within a given geographic area.

This case study focuses on the planning process for a profit-sharing program in one former Kodak division (the company has since reorganized). At the time of the study, the division employed approximately 140 individuals, engaged in producing, marketing and distributing specialty chemicals. Unit human resource managers knew that a proposal from an individual unit to alter its pay strategy, and create a significant difference from to other units, would run counter to the traditional policy of conformance across units. Yet, the unit's human resource management believed that profit-sharing might be highly effective in light of the unit's business strategy. Thus, they approached the profit-sharing decision as a business plan, similar to business plans in marketing, production or finance. Such business plans typically have three components: (1) Demonstrate the investment's link to the organizational and function strategy; (2) Conduct a return-on-investment (ROI) analysis; and (3) Define and analyze critical issues affecting the overall success or failure of the program. These three steps implement the investment model shown in Figure 1 by explicitly identifying the resources, programs, and outcomes likely to result from the program.

\section{Link With Organizational and Functional Strategy}

This step focused on the outcomes of the profit-sharing proposal. First, the strategic intent of the division was identified, including the organizational capabilities deemed necessary to accomplish division goals. It was determined that a successful profit-sharing plan could motivate and support the capabilities desired in the division. Second, the role of the profitsharing plan within the human resource functional strategy was examined. Planners considered questions such as: 
* Do we have the right development processes to build individual/team capabilities needed to support the goals of the profit-sharing program?

* Do our selection processes provide the appropriate number and types of individuals with a mindset consistent with the goals of the profit-sharing plan?

* Are our work systems designed to empower individuals to carry out the behaviors necessary to produce the organizational results that drive the profitsharing plan? Does the performance measurement system provide sufficient opportunity for evaluation, feedback and coaching to allow employees to strive for the goals of the plan?

* Does the profit-sharing plan support and integrate with the values and principles the division formally and informally communicates to its employees?

* Does the profit-sharing plan properly link with other special recognition programs to ensure timely and consistent reinforcement of desired behaviors?

While no quantitative answer to these questions could be derived, this process produced a general belief among key decision makers that profit sharing could support the division's strategic goals. It also identified several key outcomes that could be evaluated to determine if the profit-sharing plan actually paid off. However, it left decision-makers wondering just how much of an improvement in employee performance and division profits was necessary to justify the program. This question logically led to the second step.

\section{Return-On-Investment (ROI) Analysis}

The profit-sharing plan was designed as an "add-on". This meant that participation was not contingent on employees contributing a portion of their base salary, either through a salary reduction or a reduction in future salary increases. Instead, the plan would create 
a pool of funds for distribution to employees, with the size of the pool depending on the degree to which earnings exceeded an annual target. Meeting the target was the baseline expectation, so no additional payout would be associated with achieving the target earnings level.

Insert Table I Here

\section{Traditional Cost and Program-Based Analysis}

The payout formula for the different levels of earnings performance is shown in Table I. The analysis shows five different performance levels represented by letters in Column 1, with each level corresponding to an increment in net earnings beyond target. Net earnings are measured according to the financial statements of the unit at the end of each year. The earnings increments are ordered from lowest at the top to highest at the bottom. $\$ 0.3$ Million above the target earnings level for the unit was established as a buffer zone, for which there is a payout of $\$ 0$. Each earnings level corresponds to a Payout level (Column 3) derived from a formula developed by compensation specialists at Kodak. The payout as a proportion of incremental earnings increases as earnings rise, reflecting an attempt to provide an incentive to achieve the highest earnings possible. In essence, the more actual earnings exceed the target, the greater the proportion of the excess earning shared by employees. Payouts are capped at $\$ 0.405$ Million.

Often, these three columns represent the only quantitative analysis applied to profitsharing plans. The main goal is to estimate a payout formula that produces payouts that are 
feasible, given the levels of pay and other performance-based recognition awards. However, taking a strategic investment perspective allows a different kind of analysis.

\section{Return-On-Investment}

Using the concepts in Figure 1, return-on-investment analysis identifies the resources invested in a program, and the valued outcomes that program will produce. Then, ROI is calculated using the following formula:

$$
\text { Return - Investment }
$$

\section{Return on investment $=$}

Investment

In this case, management believed that the incremental administrative and implementation costs of the profit-sharing program were minimal compared to the dollar payout. Therefore, the dollar payout represented the major investment, but what was the appropriate return? One might define the return as the incremental earnings in Column 2. Using this approach, returnon-investment could be calculated by dividing the incremental earnings in Column 2 by the payout level in Column 3. This produces values ranging from $178 \%$ in Row A (using $\$ 1.1$ Million as the return, and $\$ 0.0395$ Million as the investment), to $431 \%$ in Row E (using $\$ 0.6$ Million as the return, and $\$ 0.113$ Million as the investment). With such high ROI levels, it's tempting to wonder why any organization fails to implement profit-sharing!

However, there is a flaw in this logic. The entire incremental return is unlikely to be due solely to the implementation of the profit-sharing plan. Independent factors such as market changes, as well as investments in other areas such as advertising, production technology, and training all play a part in achieving high earnings. It would be incorrect to attribute the entire earnings increase solely to any one factor, including profit-sharing. 
Moreover, the proportion of incremental earnings attributed to the profit-sharing program makes a big difference in the apparent ROI of the program.

Insert Table II Here

\section{Sensitivity Analysis}

Table II applies another financial tool called "sensitivity analysis". This tool explores how sensitive are the conclusions from an analysis to differences in certain key variables. In this case, the Table shows how sensitive are the ROI values to differences in assumptions about the proportion of incremental returns attributable to the profit-sharing program. The values in the right-hand column were calculated by multiplying the minimum (or maximum) return level by the percentage shown in the second column, subtracting the corresponding minimum (or maximum) payout level, and the dividing by that payout level. The Table vividly shows that the ROI of the profit-sharing program is quite sensitive to assumptions about the percentage of earnings attributable to the program. At each performance level, if profit-sharing accounts for only about $10 \%$ of the incremental returns achieved, the payout to employees is greater than the incremental returns, producing a negative ROI level. On the other hand, if the profit-sharing program can be credited with $50 \%$ of the incremental returns, the ROI levels exceed $39 \%$, and may reach as high as $160 \%$.

At this point, Kodak human resource managers faced two important questions that had not been apparent before: (1) Is there an appropriate "hurdle rate" for human resource investments, beyond which they should receive investment dollars, and below which such investments should flow to other opportunities? If so, what should that "hurdle rate" be? 
(2) What proportion of incremental returns can be attributed to the profit-sharing plan at various levels, and does this proportion rise or fall as the incremental returns rise and fall? These questions provided a new perspective for enhancing the strategic partnership between line and human resource managers. Kodak's division human resource planners sought out the advice of line managers and company financial experts. Their objective was to work with managers to use the common language of the return-on-investment analysis to stimulate communication about the relationship between the profit-sharing decision and division strategy.

The return-on-investment framework provided a useful bridge, helping managers outside the human resource and compensation areas vividly understand the implications of profitsharing for division financial strategies, and helping human resource and compensation managers better frame questions and interpret responses. In answer to the first question, it was determined that human resource investments should be subject to the same financial cost of capital or hurdle rate applied to investments in the division carrying a similar level of risk. Setting this rate is always partially a subjective decision (see any financial management textbook, such as Helfert, 1987, Chapter 6 for a discussion of the issues involved in determining the cost of capital). While the precise factors used to estimate such hurdle rates, and the actual rate derived are proprietary, a $20 \%$ hurdle rate provides a realistic illustration of the results.

Insert Table III Here 


\section{Break-Even Analysis}

Table III shows how a third financial tool--break-even analysis based on the $20 \%$ hurdle rate was used to simplify the analysis. Break-even analysis simplifies the results of the sensitivity analysis by using one critical value for the key variable. In this case, the key value is the $20 \%$ hurdle rate for ROI. Using this value, it is possible to calculate precisely the percentage of incremental earnings that must be attributed to the profit-sharing program, in order to "break-even" with the target hurdle rate. For example, the minimum payout under performance level $\mathrm{D}$ is $\$ 0.059$ Million. The following formula shows how the target ROI hurdle relates to the break-even earning level necessary to achieve that hurdle rate:

$$
\text { Earnings Attributed to Plan - Payout }
$$

Target ROI Rate $(20 \%)$

Payout

Substituting the value of $\$ 0.059$ for the Payout in this formula produces a value for "Earnings Attributed to Plan" of $\$ 0.0708$ Million (equal to 1.2 times $\$ 0.059$ ). Dividing the $\$ 0.0708$ Million value by the minimum incremental earnings level at Performance Level D ( \$0.3 Million) gives $23.6 \%$, the proportion shown in Table III at the minimum of the range corresponding to performance level D. This is the break-even proportion at that performance level. That is, if $23.6 \%$ of incremental earnings are due to profit-sharing, the return on investment equals exactly $20 \%$. Using only the information contained in Table I, human resource and line managers found it difficult to agree on a suitable framework for evaluating profit-sharing alternatives. With the information displayed as shown in Table III, it was clearer to both human resource and line management exactly what was required for the profitsharing program to pay off at a level justifying the investment. 
Incorporating the Analysis Into Decisions

The data of Table III helped Kodak managers realize that the profit-sharing investment required a high proportion contribution to incremental earnings from employees. This had not been clear from the data reported in Table I, which tended only to emphasize the costs of the program. The analysis raised questions as to whether the profit-sharing plan would generate these contributions, and the pattern of managers' reactions was very interesting. Managers reasoned that the probability of the profit sharing plan contributing to incremental earnings increased as the overall level of incremental earnings increased. Thus, even though higher unit earnings implied higher proportional payout levels, managers felt it was more likely that the profit-sharing plan would be responsible for the incremental earnings at the higher levels. Their logic seemed to be, "the likelihood of other factors (such as new equipment, better marketing, and increased cost control with suppliers) moving us marginally beyond our targets is much greater than the likelihood of them moving us well beyond our targets. At the lower incremental earnings levels, it's difficult to conclude with much confidence that the profitsharing program contributed over $20 \%$ of earnings. However, if this division managed to achieve earnings levels in the range of A or B, such high earnings increments would have to come from less tangible factors that employees would bring to the division." The likelihood of achieving returns at levels A and B was believed to be lower, but for that reason managers felt more comfortable attributing up to $50 \%$ of the credit for such high earnings levels to the profit-sharing program. Managers felt that it was more likely the Division could achieve incremental earnings in the lower ranges, but less likely that the contribution of profit-sharing to such earnings was sufficient to justify the investment at that level. 
The Role of Performance Measurement and Management

How can planners accurately determine the proportion of incremental earnings that is attributable to employees behaving differently because of the profit-sharing program? Certainly, it is never possible to accurately pinpoint the dollar value of employee performance, and even more difficult to predict the dollar value of performance changes resulting from new programs (Boudreau, 1988, 1991). Break-even analysis helps by showing that it is not necessary to predict the exact level of improved performance, only whether it exceeds the threshold necessary to justify the investment. While this simplifies the task, it is still necessary to consider whether performance improvements can indeed exceed the threshold. At this point, performance measurement and management becomes a critical input to the strategic planning process.

Kodak employs performance management processes in which supervisors and employees are continuously in contact regarding employee performance. Supervisors are expected to act as coach and manager. The supervisor and employee meet at least annually to discuss the employee's performance, and to summarize the discussion in the form of a performance report. The report evaluates the employee's performance along a variety of dimensions including quantity and quality of results, teamwork, job skills, versatility and communications. There are several ways that information from such a system can help with the critical judgments necessary to decide on profit sharing.

Using the amounts shown in Table III, managers can specifically discuss what kinds of changes in performance might produce the dollar values necessary to achieve the hurdle rate. Managers could consider how much performance must increase on average to achieve the needed increment. For example, the needed profit-sharing program must generate at least 
$\$ 0.1356$ million, or $22.6 \%$ of the incremental earnings at the maximum payout of Performance Level D. Because the Division employs 140 individuals, the needed average increment in performance per person is $\$ 0.1356$ million divided by 140 individuals, or $\$ 900$ per individual. For illustration, assume that the average compensation and benefits per person in the division at the time of this study was $\$ 30,000$. If we assume that the average employee's performance is sufficient only to cover these direct employment costs (a conservative assumption), then the needed $\$ 900$ increment per individual represents a three percent increase in average performance. Managers can now examine the dimensions of performance to determine whether the potential for this kind of performance increase exists. Then, they could use the coaching process to explore employee reactions to the possible profit-sharing program, and their likely motivation to increase their behavior along these dimensions.

Performance measurement could also be used to evaluate the effects of profit-sharing once implemented. Research examining the link between the existence of profit-sharing programs and the value-added or other financial indicators of the unit has generally found a positive association, with an average result that profit-sharing is associated with a $7.4 \%$ increase (Weitzman \& Kruse, 1991). However, this perspective is of limited value to determine whether the program actually affected employees' behaviors. A more direct approach would use the performance measurement system. If the division achieves incremental earnings above target, there should be a corresponding increase in one or several dimensions of employee performance related to increased earnings. If employee performance decreases or stays constant while earnings increase, this suggests that the increase was not largely due to changes motivated by the profit-sharing program. However, this assumes that the performance management system can provide information about employee behaviors affected 
by profit-sharing, and likely to result in higher unit profits. Such before-after evaluations do not completely control for other factors (such as new technology) that may contribute simultaneously to employee performance and profit levels, and one can improve the analysis by comparing the results with a unit that is similar in many respects but does not receive the profit-sharing program. In light of both the upside and downside risks suggested in Table II, investing in such pilot studies and controlled experiments may be quite justified to improve the quality of such decisions in many organizations.

At the time of this study, however, the Division used a "numberless" performance measurement system, focusing on goal setting and identifying individual development needs. The intent was to focus the process away from generating a number, and toward recognizing accomplishment and identifying improvement opportunities. Development, rather than evaluation was the goal. For decisions requiring evaluation, such as pay, a forced-ranking system was used, but it was administered and constructed completely separately from the numberless system. Because neither of these systems provides information that could be used to track changes in the level of performance, they would not have been valuable for examining the effects of profit-sharing (or any other intervention for that matter) on group-level employee performance.

This illustrates the strategic tradeoffs that are made when designing performance measurement systems. Murphy \& Cleveland (1991, Chapter 11) summarized the goals of appraisal systems into: (1) Providing pay and/or promotion rewards; (2) Providing information to employees about strengths and weaknesses; (3) Determining the effectiveness and value of existing or proposed human resource management activities; and (4) Documenting and creating a "paper trail" to justify personnel actions. They recommended that managers design 
performance appraisal systems to achieve specific goals, which may or may not be mutually compatible. While Kodak's "numberless" system may indeed focus attention on development (Goal \#2 above), and Kodak's ranking system may enable the hard choices necessary to distribute rewards (Goal \#1 above), strategic program evaluation (Goal \#3) often requires a system that generates evaluations reflecting performance levels, comparable over time and between groups. The performance information produced determines the strategic decisions that can be supported, and the return-on-investment approach highlights the importance of this third goal, which is often ignored by organizations rushing to create appraisal systems focused on the other three goals.

How can organizations design performance measurement systems to accomplish the third goal? By tailoring systems to the key strategic decisions facing the organization. The dimensions used in the appraisal process should be easily traceable to changes in valued organizational outcomes such as earnings. Examples of behaviors that managers may expect will be motivated by profit-sharing programs might include increased efforts to cut expenses (such as using less costly hotels or fewer unnecessary supplies), being more efficient (such as using production materials more frugally, reducing needless production steps, or pushing suppliers to be more competitive), or generating greater sales (such as following up with customers and encouraging customers to consider high-revenue product alternatives).

The measures used to track the performance dimensions should allow comparison across groups of employees. This requirement favors systems that produce numbers that can be easily compared among individuals and across units. The most straightforward approach to generating such numbers is probably to measure outcomes already scaled in comparable units, such as expenses, sales, or number of units produced. However, even performance 
measurement systems that rely on judgments can be made more comparable. Global judgments of performance are difficult to compare across units. However, if the judgments are scaled using specific anchors or critical incidents like the ones described above, and if the scales are common across different units and time periods, then evaluating program effectiveness becomes easier. It seems possible that in many cases the performance measurement criteria that serve best to determine individual rewards or provide individual feedback may also be the criteria that are most valuable in assessing program effectiveness. The key is to design the measurement system so that the information can be captured, tracked and compared as programs are implemented and changed.

Thus, the return-on-investment perspective suggests that to adequately evaluate compensation programs such as the profit-sharing plan, the performance management system must reflect the strategic decisions, and the key strategic outcomes of interest to the unit. Such a perspective is very different from that taken by many organizations which may emphasize the administrative, rather than strategic aspects of performance management. Such a perspective also suggests that without a performance management system attuned to strategic decisions, those decisions must often be based merely on management beliefs, with little hard information to support or refute them. While such an approach is not uncommon, even in areas other than human resource management, the lack of such performance information probably can only hamper the ability of human resource managers to effectively communicate using information compatible with strategic financial goals. Even when it is not possible to reflect all the goals in a single performance measurement system, the payoff from improved program planning may well justify the additional investment to create systems that are more closely linked to strategic decisions. 
Finally, the return-on-investment analysis suggests specific ways to modify the profitsharing plan to enhance its investment value. For example, by lowering the payout for incremental earnings levels such as $C$ and $D$, the break-even proportion of earnings necessary to reach the $20 \%$ hurdle rate is also reduced. Conceivably, human resource and line managers could work together to change the payout formula until a satisfactory break-even level is achieved at all incremental earnings targets. Thus, the financial perspective allows managers not only to communicate about decisions to adopt strategies, but to more precisely plan and construct the strategies themselves.

At Kodak, the return-on-investment analysis showed more precisely how information about employee performance can link to key human resource investment decisions. It is likely that such analyses will prompt line and human resource managers to reconsider their appraisal systems, asking "how does this system help me predict and evaluate the effects of our human resource investments on key organizational goals?" The challenge is to respond with systems that clearly reflect the link between employee behaviors and unit goals.

Effects of Return-On-Investment Analysis on Kodak's Profit-Sharing Decision

In the end, Kodak managers decided not to implement the profit-sharing program within the Division. Two issues seemed to be key to this decision. First, internal equity was a consideration because of the geographic proximity and work similarity of the company's different units. Such an add-on in one unit would likely be perceived as unfair by other employees. Second, external equity was a consideration because Kodak's company-wide pay levels were already well above other employers in the community. There was concern that the add-on program would inflate the pay level, bringing it out of line with the rest of the community. 
In one sense, these two concerns reflect a broader return-on-investment analysis. Instituting a profit-sharing program would not only affect the employees participating in the plan, but would be observed and affect the thousands of other Kodak employees in other units. Using the same kinds of analyses depicted in Tables II and III, one could estimate how much of a drop in employee performance, or an increase in costs due to disruptive attitudes, would be needed to offset the projected gains within the unit from the profit-sharing program. This perspective was never formalized, however, so it is impossible to know whether such effects would indeed offset the gains.

The ability of individual profit and cost centers to establish unique approaches to some of their human resource practices was one objective of the restructuring. It was felt that the traditional reluctance to break the pattern at the unit level was one factor that prevented Kodak from adapting quickly to competitive pressures. In this case, however, the traditional concerns won out. Still, the return-on-investment analysis was believed to have had a significant effect. In the past, proposals for unit-specific human resource programs had been summarily dismissed with little or no review beyond the immediate unit, because it was assumed that corporate management would never approve such programs. In this case, the profit-sharing program was given careful consideration by corporate management, and was reviewed by the company president. Managers seemed to believe that the program was likely to produce a valuable return for the unit, and were thus forced to directly confront the fact that a policy of consistency across units might be forcing the organization to give up lucrative opportunities. In the past, consistency had been valued almost as an end in itself. This analysis helped managers to better understand the relationship between corporate values, strategy, compensation strategy, and employee performance management. 
Boudreau, J. W. (1984). Decision theory contributions to HRM research and practice. Industrial Relations, 23, 198-217.

Boudreau, J. W. (1988). Utility analysis. In L. Dyer (Ed.) Human resource management: Evolving roles and responsibilities. Vol. 1, ASPA/BNA Handbook of Human Resource Management, pp. 1-125--1-186. Washington, D.C.: Bureau of National Affairs.

Boudreau, J. W. (1991). Utility analysis for decisions in human resource management. In M. D. Dunnette \& L. M. Hough (Eds.) Handbook of Industrial and Organizational Psychology, (2nd ed.), Vol. 2. Palo Alto: Consulting Psychologists Press, pp. 621745.

Helfert, E. A. (1987). Techniques of financial analysis (6th ed.). Homewood, IL: Richard D. Irwin.

Lawler, E. E. III (1981). Pay and organizational development. Reading, MA: AddisonWesley

Milkovich, G. T. \& Newman, J. (1990). Compensation. Homewood, IL: Richard D. Irwin.

Murphy, K. R. and J. N. Cleveland (1991). Performance appraisal: an organizational perspective. Needham Heights, MA: Allyn \& Bacon.

Weitzman, M. L. \& Kruse, D. L. (1990). Profit sharing and productivity. In A. S. Blinder (Ed.), Paying for productivity. 
Table I

Typical Quantitative Description of Profit-Sharing

(1)

\section{Performance \\ Level}

E

$\mathrm{D}$

C

B

A
(2)

(3)
Profit-Sharing

Payout

less than \$0.3 Million

$\$ 0.0$

$\$ 0.3$ to $\$ 0.6$ Million

$\$ 0.7$ to $\$ 0.8$ Million

$\$ 0.167$ to $\$ 0.19$ Million

$\$ 0.9$ to $\$ 1.0$ Million

$\$ 0.267$ to $\$ 0.295$ Million

$\$ 0.059$ to $\$ 0.113$ Million

$\$ 0.395$ to $\$ .405$ Million

Note: The dollar values shown here illustrate the relationships among the profit-sharing plans. However, the actual dollar values have been disguised to protect confidential information. 
Table II

Sensitivity Analysis of Profit-Sharing

Return on Investment (ROI)

Amount of

Incremental Earnings

Performance

Level

D

C

B

A

\section{ROI Range}

Profit-Sharing

$10 \%$

$30 \%$

$50 \%$

$70 \%$

$90 \%$

$10 \%$

$30 \%$

$50 \%$

$70 \%$

$90 \%$

$10 \%$

$30 \%$

$50 \%$

$70 \%$

$90 \%$

$10 \%$

$30 \%$

$50 \%$

$70 \%$

$90 \%$
$-5 \%$ to $-5 \%$

$52 \%$ to $59 \%$

$154 \%$ to $165 \%$

$256 \%$ to $272 \%$

$358 \%$ to $378 \%$

$-58 \%$ to $-58 \%$

$26 \%$ to $26 \%$

$109 \%$ to $110 \%$

$193 \%$ to $195 \%$

$277 \%$ to $279 \%$

$-66 \%$ to $-66 \%$

$1 \%$ to $2 \%$

$69 \%$ to $70 \%$

$136 \%$ to $137 \%$

$203 \%$ to $205 \%$

Greater than $-16 \%$

Greater than $39 \%$

Greater than $95 \%$

Greater than $151 \%$
Greater than $-72 \%$ 
Table III

Break-Even Analysis for

Profit-Sharing with a $20 \%$

Investment Hurdle Rate

\section{Performance \\ Level}

D

C

B

A
$\$ 0.474$ Million, or $43.1 \%$ at minimum of range $\$ 0.486$ Million at the maximum payout

Amount and Proportion of Incremental Earnings Required to Attribute to Profit-Sharing to Achieve a $20 \%$ Target ROI Level

$\$ 0.0708$ Million, or $23.6 \%$ at minimum of range, $\$ 0.1356$ Million, or $22.6 \%$ at maximum of range

$\$ 0.2004$ Million, or $28.6 \%$ at minimum of range, $\$ 0.228$ Million, or $28.5 \%$ at maximum of range $\$ 0.3204$ Million, or $35.6 \%$ at minimum of range, $\$ 0.354$ Million, or $35.4 \%$ at maximum of range 
Figure 1

Model for Compensation Investments

\section{RESOURCES}

* Payments

* Administration

* Data Collection

* Communication

* Increased Benefits

\section{COMPENSATION}

PROGRAMS

$\begin{array}{ll}* & \text { Base Pay } \\ * & \text { Merit Systems } \\ * & \text { Profit Sharing } \\ * & \text { Gain Sharing } \\ * & \text { Benefits }\end{array}$

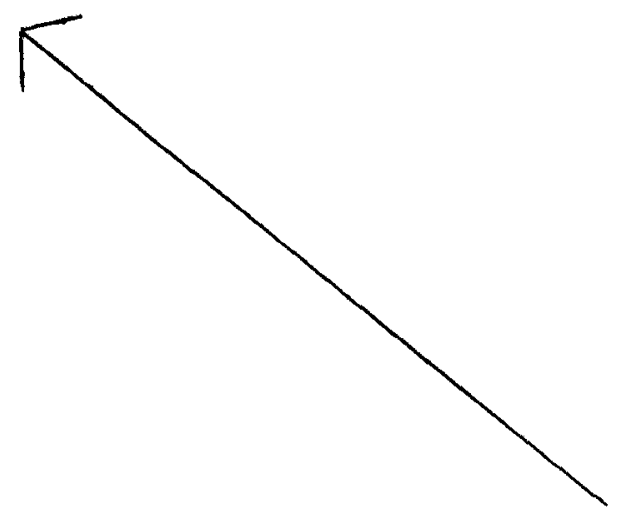

VALUED

OUTCOMES

FOR

STAKEHOLDERS

* Em ploy e e Performance

* Em plo y e e Productivity

* Em ploy e e Satisfaction

* Compensation Cost Reduction

* Line Manager Satisfaction

* H i g h e r Profitability 